\title{
Study and Comparison of Four Agent-Based Simulation Tools: Repast, SeSAm, Netlogo and GAMA \\ Wafa Mefteh \\ wafa.mefteh07@gmail.com
}

\section{ABSTRACT}

Several simulation tools have been proposed in the literature and many surveys have been realized on this. The objective of this paper is not to give a survey but to compare four principal tools which are Repast, SeSAm, NetLogo and Gama according to some evaluation criteria that I consider important when designing Adaptive Multi-Agent Systems.

\section{Indexing terms/Keywords}

Simulation Tools; Agent-Based Simulation Tools; Adaptive Multi-Agent Systems.

\section{Academic Discipline And Sub-Disciplines}

Computer sciences.

\section{SUBJECT CLASSIFICATION}

Modelling and simulation.

\section{Council for Innovative Research}

Peer Review Research Publishing System

Journal: INTERNATION JOURNAL OF COMPUTERS AND TECHNOLOGY

Vol. 13, No. 4

editorijctonline@gmail.com

www.cirworld.org/journals 


\section{INTRODUCTION}

There is some ambiguity concerning the terms "platform" and "toolkit (tool)" but generally they have been used interchangeably. In this paper, I also use these terms interchangeably. Several surveys have been done on agent simulation tools. The purpose of my work is not to present a state of the art about agent based simulation tools but to compare four principal tools according to some criteria defined later in this paper. The objective is to select the more appropriate tool to Adaptive Muli-Agent Systems (AMAS) [1] [2]. The proposed criteria are not determinist for any intended use of the simulation tool. These criteria was defined according to some characteritics that I find necessary to build simulations for Adaptive Multi-Agent Systems [3].

In this paper, I beguin by presenting the different criteria to be used. Then I describe each tool according to these criteria and Finally I give a synthesis about the comparison of these tools.

\section{CRITERIA OF COMPARISON}

In this section, I describe eight criteria of comparison (table 1). Some of these criteria are inspired from [4] and the others are proposed according to my objective from realising simulations. For each criterion, I define a set of values which can assigned to this criterion. For each value, I give a rate according to my objective from verifying the criterion. For example, if I consider a criterion $\mathbf{C}$ which can has as values: $c 1$ and $c 2$. If $c 1$ interests me more than $c 2, I$ assign a more important rate to $c 1$ than $c 2$. In the following, I use four rates which are:

\begin{tabular}{|l|l|}
\hline rate & Used for \\
\hline 0 & $\begin{array}{l}\text { Non-interesting values. The tool which has this value, for one or more criteria, } \\
\text { cannot be selected. } \\
\text { Very quite interesting values. }\end{array}$ \\
50 & $\begin{array}{l}\text { Quite interesting values. } \\
\text { interesting values. }\end{array}$ \\
\hline
\end{tabular}

Table 1 describes the different criteria of comparison which I will use them later to compare the four tools. For each criterion, I give the possible values that this criterion can obtain and the rate assigned to each value.

\begin{tabular}{|c|c|c|c|}
\hline Criteron Name & Criteron Description & Possible Values & Values Rates \\
\hline Availibility & $\begin{array}{l}\text { Is the tool free and open source or not? The } \\
\text { availability of the code source enables to } \\
\text { integrate new plug-ins if necessary to well } \\
\text { simulate agents in some cases. }\end{array}$ & $\begin{array}{l}\text { V1 }=\text { Free and available } \\
\text { V2 }=\text { Free and not available. }\end{array}$ & $\begin{array}{l}\text { Rate of } \mathrm{V} 1=100 . \\
\text { Rate of } \mathrm{V} 2=0 .\end{array}$ \\
\hline Project Activity & $\begin{array}{l}\text { Does the tool is used in research ? This } \\
\text { criterion enables to evaluate the level of } \\
\text { professionalism of the tool. Taking } \\
\text { advantages from other users will probably } \\
\text { help to better exploit it. }\end{array}$ & $\begin{array}{l}\text { V1 = Used in research. } \\
\text { V2 = Not used in research. }\end{array}$ & $\begin{array}{l}\text { Rate of } \mathrm{V} 1=100 . \\
\text { Rate of } \mathrm{V} 2=20 .\end{array}$ \\
\hline Complexity Level & $\begin{array}{l}\text { This criterion is to evaluate the level of } \\
\text { complexity to handle the tool. This includes } \\
\text { the language required to develop a model } \\
\text { and to run a simulation, and if there are } \\
\text { sufficient documentation and demonstration } \\
\text { simulation models. By documentation, I am } \\
\text { looking for manuals that explain how to use } \\
\text { the toolkit. By demonstration simulation } \\
\text { models, I am looking for examples of building } \\
\text { and running simulation models. The } \\
\text { existence of a well documentation and } \\
\text { demonstration simulation models help to } \\
\text { quickly understand the tool and how to build } \\
\text { a simulation. }\end{array}$ & $\begin{array}{l}\text { V1 }=\text { Simple } \\
\text { V2 }=\text { Medium } \\
\text { V3 }\end{array}$ & $\begin{array}{l}\text { Rate of } \mathrm{V} 1=100 . \\
\text { Rate of } \mathrm{V} 2=50 \\
\text { Rate of } \mathrm{V} 1=0 .\end{array}$ \\
\hline Generality & $\begin{array}{l}\text { Most of tools are dedicated to a particular } \\
\text { field of applications. I am interested by a tool } \\
\text { that is as general as possible to solve } \\
\text { different types of complex systems which }\end{array}$ & $\begin{array}{l}\text { V1 }=\text { Specialized } \\
\text { V2 }=\text { Litle specialized } \\
\text { V3 }=\text { General }\end{array}$ & $\begin{array}{l}\text { Rate of } \mathrm{V} 1=0 . \\
\text { Rate of } \mathrm{V} 2=20 \\
\text { Rate of } \mathrm{V} 1=100\end{array}$ \\
\hline
\end{tabular}




\begin{tabular}{|c|c|c|c|}
\hline & can be related to different domains. & & \\
\hline $\begin{array}{l}\text { Possibility of } \\
\text { Using Diagrams }\end{array}$ & $\begin{array}{l}\text { This criterion permits to know if I can design } \\
\text { and orchestrate simulation experiments via } \\
\text { diagrams. It is an interesting criterion } \\
\text { because the possibility of using diagrams } \\
\text { (UML like) to describe the system to be } \\
\text { simulated will further facilitate the task of the } \\
\text { designer using the simulation tool. }\end{array}$ & $\begin{array}{l}\text { V1 = With diagrams } . \\
\text { V2 = Without diagrams. }\end{array}$ & $\begin{array}{l}\text { Rate of } \mathrm{V} 1=100 . \\
\text { Rate of } \mathrm{V} 2=20\end{array}$ \\
\hline Dynamic Tuning & $\begin{array}{l}\text { This criterion indicates if the simulation } \\
\text { parameters can be modified in real time. It } \\
\text { will be interesting for the designer if he can } \\
\text { modify the simulation parameters when } \\
\text { simulation is running in order to converge the } \\
\text { system towards the functional adequacy. }\end{array}$ & $\begin{array}{l}\text { V1 = Dynamic tuning. } \\
\text { V2 = No Dynamic tuning. }\end{array}$ & $\begin{array}{l}\text { Rate of } \mathrm{V} 1=100 . \\
\text { Rate of } \mathrm{V} 2=0 .\end{array}$ \\
\hline Measurement & $\begin{array}{l}\text { This criterion is to verify if the tool proposes } \\
\text { or not analysis mechanisms. I am interested } \\
\text { by a tool that has analysis tool integrated in } \\
\text { order to help the designer to analyse the } \\
\text { behaviours of the agents. }\end{array}$ & $\begin{array}{l}\text { V1 }=\text { With analysis } \\
\text { V2 }=\text { Without analysis. }\end{array}$ & $\begin{array}{l}\text { Rate of } \mathrm{V} 1=100 \\
\text { Rate of } \mathrm{V} 2=0\end{array}$ \\
\hline Agents Type & $\begin{array}{l}\text { This criterion verifies if the tool enables the } \\
\text { simulation of communicating agents or } \\
\text { situated agents or both [5]. To simulate } \\
\text { Adaptive Multi-Agent Systems, I am } \\
\text { interested to Communicating agents. }\end{array}$ & $\begin{array}{l}\text { V1 = Only situated agents. } \\
\text { V2 = Only communicating } \\
\text { agents. } \\
\text { V3 = Communicating and } \\
\text { situated agents. }\end{array}$ & $\begin{array}{l}\text { Rate of } \mathrm{V} 1=0 . \\
\text { Rate of } \mathrm{V} 2=90 . \\
\text { Rate of } \mathrm{V} 3=100 .\end{array}$ \\
\hline
\end{tabular}

\section{GENERAL DESCRIPTION OF REPAST, SESAM, NETLOGO AND GAMA}

In this section, I give a general description of Repast, Sesam, Netlogo and Gama. For each tool, I describe the different elements of comparison proposed in the previous section.

Repast (http://repast.sourceforge.net/repastl 3) was developed at the University of Chicago's Social Science Research Computing Lab specifically for creating agent-based simulations in social sciences. It borrows many concepts from the Swarm which was the first re-usable software tool created for agent based modelling and simulation. Swarm was developed at the Santa Fe Institute in 1994 (for more information, see http://www.swarm.org) .

Repast simulations typically have at least two classes:

- Agent class: describes the behaviour of the agents.

- Model class: coordinates the set-up and running of the model. $s$

Table 2 describes Repast according to the different defined elements of comparison.

\begin{tabular}{llc}
\hline Criteron Name & Description & Assigned Note \\
\hline Availibility & Repast is free and open source. & 100 \\
Project Activity & $\begin{array}{l}\text { Repast has been under continuous development for over } 10 \text { years and it was } \\
\text { used by many researchers. }\end{array}$ & 100 \\
Complexity Level & $\begin{array}{l}\text { Repast supports Java programming. Repast models can be developed in many } \\
\text { languages including Java, C sharp, Managed C++, Visual Basic.Net, Managed } \\
\text { Lisp, Managed Prolog, and Python scripting. Repast provides few documentation } \\
\text { and few demonstration simulation models. }\end{array}$ & 0 \\
Generality & $\begin{array}{l}\text { Repast was clearly intended to support principally one domain which is "social } \\
\text { science" and includes tools specific to this domain. }\end{array}$ & 20 \\
Possibility & $\begin{array}{l}\text { Repast enables the description of agent behaviours via a flowchart representing } \\
\text { the different properties of the agent and the sequence of the different tasks } \\
\text { realized by the agent during its life cycle. }\end{array}$ & 100 \\
Dynamic Tuning & $\begin{array}{l}\text { Repast enables users to dynamically access and modify agent properties, agent } \\
\text { behavioural equations, and model properties at run time. }\end{array}$ & 100 \\
\hline
\end{tabular}




\begin{tabular}{lll}
\hline Measurement & Repast does not integrate analysis mechanisms. & 0 \\
Agents Type & Repast enables the simulation of situated agents. & 0 \\
\hline
\end{tabular}

Sesam (http://www.simsesam.de/) is a generic environment for the development and simulation of Multi-Agent models. The main focus is to enable to construct models by visual programming. Sesam was developed at the University of Wurzburg and applied in several projects in different application domains.

The main entities in a Sesam model are:

- Agents: they consist of a body containing body variables and have a behaviour described by activity diagrams.

- Resources: they are like agents, except that they don't have a behaviour and they should be used for passive entities in the model.

- The World: it is a kind of agent class with a special role in interaction: it forms the basis for the representation of all environmental dynamics and structure that can not be captured in agents and resources.sss

Table 3 describes Sesam according to the different defined elements of comparison.

\begin{tabular}{|c|c|c|}
\hline Criteron Name & Description & Assigned Note \\
\hline Availibility & Sesam is free and open source. & 100 \\
\hline Project Activity & Sesam is used by many researches and it is used in education. & 100 \\
\hline Complexity Level & $\begin{array}{l}\text { Sesam supports visual programming. It has graphical-based programming } \\
\text { capabilities which are much more simple to learn and use than traditional } \\
\text { programming languages. Sesam provides several documentations, tutorials ans } \\
\text { demonstration simulation models and tutorials. It has also project wikis as part of } \\
\text { user support. }\end{array}$ & 100 \\
\hline Generality & $\begin{array}{l}\text { Sesam is a general purpose agent based platform. It is not geared toward } \\
\text { special domains. It is also oriented towards teaching computer simulation. }\end{array}$ & 100 \\
\hline $\begin{array}{l}\text { Possibility of } \\
\text { Using Diagrams }\end{array}$ & $\begin{array}{l}\text { Sesam provides the possibility of describing the agent behaviour using an activity } \\
\text { diagram. Each activity is then defined using a visual programming. A list of } \\
\text { configurable functions allows to link actions to nodes and conditions to transitions } \\
\text { between nodes. The design of agents becomes very quick and intuitive. }\end{array}$ & 100 \\
\hline Dynamic Tuning & $\begin{array}{l}\text { Sesam permits to realize experimentations which means the possibility of } \\
\text { launching many simulation simultaneously and modifying the value of one or } \\
\text { more parameters. It is possible to modify the simulation parameters during } \\
\text { runtime. }\end{array}$ & 100 \\
\hline Measurement & $\begin{array}{l}\text { Sesam has an analysis editor which allows to create an analyser that monitors } \\
\text { the simulation. The simulation results can be displayed as graphs or stored in a } \\
\text { file in tabular form. }\end{array}$ & 100 \\
\hline Agents Type & Sesam enables the simulation of both situated and communicating agents. & 100 \\
\hline
\end{tabular}

NetLogo (http://ccl.northwestern.edu/netlogo/) was first created in 1999 by Uri Wilensky at the Center for Connected Learning and Computer-Based Modeling, then at Tufts University in the Boston area. Netlogo is a multi-agent programming language and modelling environment for simulating natural and social phenomena.

Netlogo manipulates:

- Turtles: which are agents.

- Patches: objects in turtles environment. 
Table 4 describes Netlogo according to the different defined elements of comparison.

\begin{tabular}{|c|c|c|}
\hline Criteron Name & Description & Assigned Note \\
\hline Availibility & Netlogo is free and open source. & 100 \\
\hline Project Activity & Netlogo is used by thousands of students, teachers and researchers worldwide. & 100 \\
\hline Complexity Level & $\begin{array}{l}\text { Netlogo supports programming in Logo Dialects extended to support agents. It is } \\
\text { built-in graphical interfaces and comprehensive documentation. In spite of } \\
\text { Repast, Netlogo has extensive documentation, tutorials and a models library } \\
\text { which is a large collection of pre-written simulations that can be used and } \\
\text { modified. }\end{array}$ & 50 \\
\hline Generality & $\begin{array}{l}\text { Netlogo was intended as an educational tool. It helps beginning users getting } \\
\text { started authoring models. Netlogo has a primary specialization towards the social } \\
\text { and natural sciences. }\end{array}$ & 20 \\
\hline $\begin{array}{l}\text { Possibility of } \\
\text { Using Diagrams }\end{array}$ & $\begin{array}{l}\text { Netlogo does not offer the possibility of describing the agents behaviours via } \\
\text { diagrams. }\end{array}$ & 20 \\
\hline Dynamic Tuning & $\begin{array}{l}\text { Netlogo does not provide the possibility of changing simulation parameters at } \\
\text { runtime. It should stop the simulation then adjust the "tolerance" slider to a new } \\
\text { value then start the model running again. }\end{array}$ & 0 \\
\hline Measurement & Netlogo does not integrate analysis mechanisms. & 0 \\
\hline Agents Type & $\begin{array}{l}\text { There really is no agent in NetLogo. This platform permits only to create a } \\
\text { program for manipulating objects in a two-dimensional space. }\end{array}$ & 0 \\
\hline
\end{tabular}

Gama (https://code.google.com/p/gama-platform/wiki/GAMA?tm=6) is a simulation platform that integrates geographical information data. It aims at providing field experts, modellers, and computer scientists with a complete modelling and simulation development environment for building spacially explicit multi-agent simulations. It is being developed by several French and Vietnamese research teams under the umbrella of the IRD/UPMC International Research Unit UMMISCO since 2007.

The Gama model is composed of four sections:

- Global: the global agent of a Gama model.

- Entities: the definition of the different species which are used to specify the structure and behaviours of agents.

- Environment: contains definitions of environments. Gama supports three types of topologies for environments: continuous, grid and graph.

- Experiment: defines experiments to run.

Table 5 describes Gama according to the different defined elements of comparison.

\begin{tabular}{llc}
\hline Criteron Name & Description & Assigned Note \\
\hline Availibility & Gama is free and open source. & 100 \\
Project Activity & $\begin{array}{l}\text { Compared with the tools presented above, it is somewhat less used by other } \\
\text { researchers. Gama provide several documentation and demonstration simulation } \\
\text { models. Gama provides also video presentations and many tutorials. }\end{array}$ & 100 \\
Complexity Level & $\begin{array}{l}\text { Gama provides a complete modeling language, GAML, for modeling agents and } \\
\text { environments. It is a language simple to use. Gama provides several } \\
\text { documentations, tutorials ans demonstration simulation models. It has also } \\
\text { project wikis as part of user support. }\end{array}$ & 50 \\
Generality & $\begin{array}{l}\text { Gama is a generic platform which permits the simulation of many different } \\
\text { systems. }\end{array}$ & 100 \\
Possibility & $\begin{array}{l}\text { Gama does not enables the description of the agent behaviour via diagrams. But, } \\
\text { it permits to define in graphical mode a simulation as a whole with the } \\
\text { environment, entities, etc. }\end{array}$ \\
Dynamic Tuning & Gama permits the modification of simulation parameters at runtime. & 20 \\
\hline
\end{tabular}




\begin{tabular}{lll}
\hline Measurement & Gama provides analysis mechanisms in batch mode. & 100 \\
Agents Type & Gama supports communicating agents. & 100 \\
\hline
\end{tabular}

\section{SYNTHESIS}

According to this comparison (figure 1), Sesam looks as an excellent tool to simulate Adaptive Multi-Agent Systems. It is a free and simple tool which enables an easily implementation of the agents. In Sesam, the agent behaviour is implemented as a set of activities and transitions between these activities and it provides a visual programming which facilitates the addition of new plug-ins to add new functionalities. Sesam enables the implementation of situated and communicating agents (other tools as Netlogo and Repast permit only the implementation of one category of agents) and it offers tools to analyse a simulation. An other important characteristic of Sesam is that it is possible to modify the data values of the agents, of the environment and of the resources during the simulation. It is a very important characteristic in our sens because it enables the designer to interact with the simulation in order to converge the behaviour of the system to the functional adequacy. Sesam provides a tool for the easy construction of complex models, which include dynamic interdependencies or emergent behaviour.

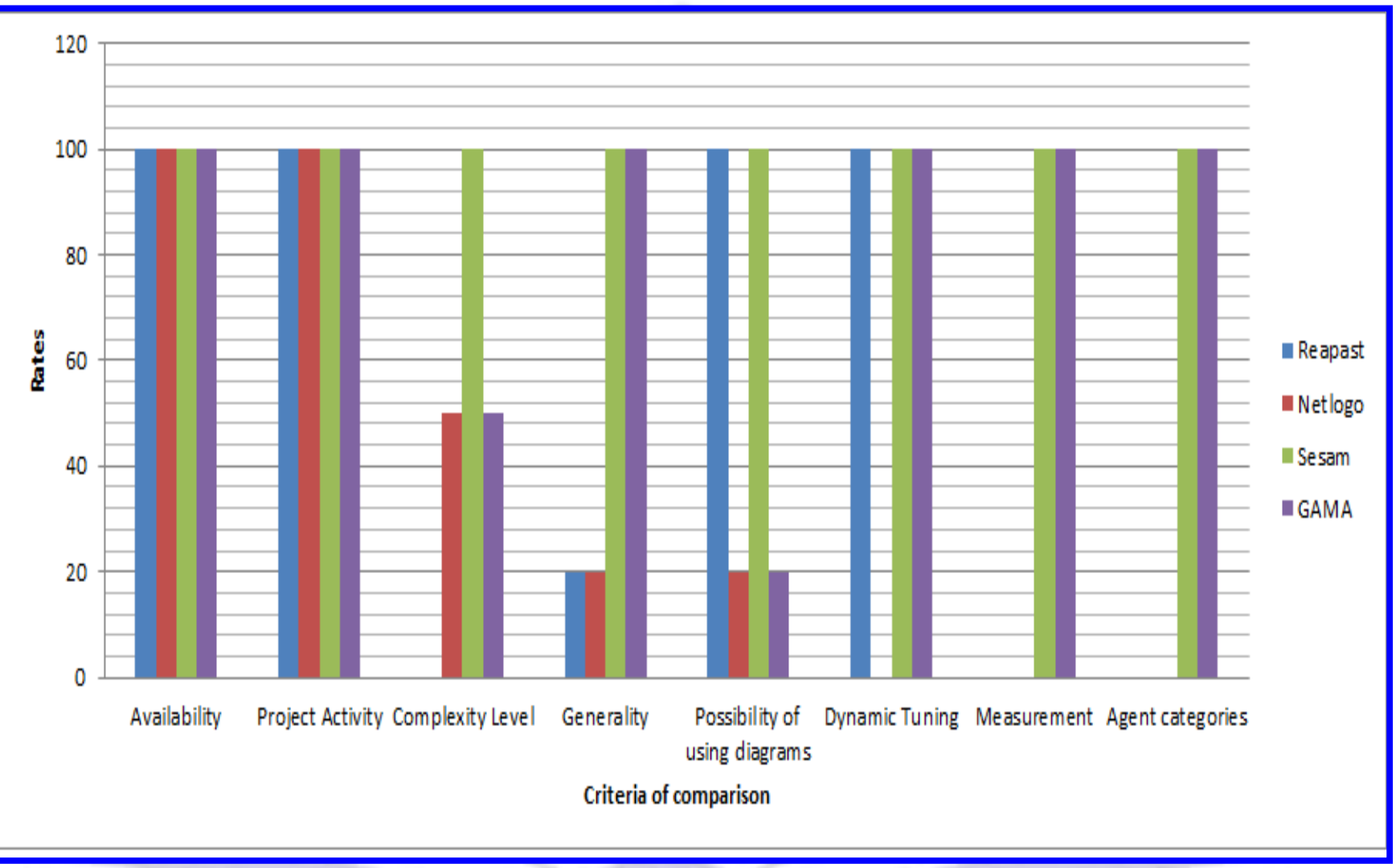

Figure 1 : Results of the Comparison.

\section{REFERENCES}

[1] Georgé, J-P., Gleizes, M-P. and Glize, P. 2003. Conception de systèmes adaptatifs à fonctionnalité émergente: la théorie des AMAS. In "Revue d'Intelligence Artificielle".

[2] Glize, P. 2001. L’Adaptation des Systèmes à Fonctionnalité Émergente par Auto-Organisation Coopérative. Habilitation à diriger des recherches, University of Paul Sabatier, Toulouse, France.

[3] Mefteh, W., Migeon, F., Gleizes, M-P. and Gargouri, F. 2012. Simulation Based Design. In 2nd International Conference on Information Technology and e-Services. 24-26 Mars 2012. Sousse, Tunisia.

[4] Cynthia, N and Gregory, M. 2009. A Survey of Various Agent Based Modeling Platforms. Journal of Artificial Societies and Social Simulation. ISSN : 1460-7425, Vol : 12, No 2.

[5] Ferber, J. 1995. Les systèmes multi agents. ,InterEditions. 